\title{
Retrospective Analysis of Pediatric Patients with Multiple Rare-Earth Magnet Ingestion: A Single- Center Experience from China.
}

\section{Yucan Zheng}

Children's Hospital of Nanjing Medical University https://orcid.org/0000-0003-2985-9727

\section{Zhihua Zhang}

Children's Hospital of Nanjing Medical University

\section{Kunlong Yan}

Children's Hospital of Nanjing Medical University

\section{Hongmei Guo}

Children's Hospital of Nanjing Medical University

Mei Li

Children's Hospital of Nanjing Medical University

Min Lian

Children's Hospital of Nanjing Medical University

Zhifeng Liu ( $\nabla$ zfliu@njmu.edu.cn )

\section{Research article}

Keywords: Children, Foreign body, Multiple magnets ingestion, Perforation

Posted Date: June 17th, 2020

DOl: https://doi.org/10.21203/rs.3.rs-35857/v1

License: (c) (1) This work is licensed under a Creative Commons Attribution 4.0 International License.

Read Full License

Version of Record: A version of this preprint was published at BMC Pediatrics on April 17th, 2021. See the published version at https://doi.org/10.1186/s12887-021-02642-y. 


\section{Abstract}

Background The aim of this study was to characterize patients with multiple rare-earth magnet ingestion in a single-pediatric medical center, reveal the harm of rare-earth magnets foreign bodies in digestive tract, and develop a clinical management algorithm.

Methods This was a retrospective review of patients with rare-earth magnets foreign bodies in digestive tract admitted to a university-affiliated pediatric medical center in China, between January 2016 to December 2019, with a subset of medical data including clinical symptoms, signs, treatments and outcomes.

Results A total of 51 cases were included in this study, including $36(70.6 \%)$ males and $15(29.4 \%)$ females. The magnets were passed naturally in $24(47.1 \%)$ patients and removed by intervention in $27(52.9 \%)$ patients, including five( $9.8 \%)$ cases by endoscopy and $22(43.1 \%)$ cases by surgery. $22(43.1 \%)$ cases had gastrointestinal obstruction, perforation, and fistula. Compared with the non-surgical group, the proportion of males in the surgical group was higher $(21 / 23$ vs $15 / 28, p=0.004)$, and the visiting time to hospital was longer (80(72) vs $26(5)$, hours, $p=0.008)$.

Conclusions The rate of surgical intervention is high in multiple rare-earth digestion cases and the consequences are serious, and a more efficient management algorithm for these cases should be needed. A policy for strictly restricted or prohibited the sale of the toys with multiple rare-earth magnets needed to put into the agenda.

Trial registration The study will be retrospectively registered.

\section{Background}

Foreign body ingestion is quite often in pediatric clinical practice, while multiple magnets ingestion is much rare. Most foreign bodies in the digestive tract without sharp edge, with moderate size and with corrosion resistance can be excreted themselves, such as toy accessories, coins, rings, etc. But $1 \%$ of the cases require surgical treatment for the foreign bodies' retention or associated complications ${ }^{1}$. Among so many different foreign bodies children swallowed, multiple magnets are unique ones. Multiple magnets especially swallowed by steps may cause serious complications such as gastrointestinal perforation, internal fistula, intestinal obstruction and even death ${ }^{2}$.

Recently years, a new kind of rare-earth magnetic toy with various colors named Buckyballs is popular among children and adolescents. Multiple rare-earth magnets with different colors can be combined to different shapes, which are attractive to kids. Differ from the traditional magnets, the Buckyballs are spherical strong magnet made of neodymium iron boron (NdFeB) -a kind of permanent magnetic material, whose magnetic force is as high as 4000 Gauss. Generally, a small Buckyball with a diameter of five millimeters can hold two coins steadily. For the past ten years, a small number of cases of intestinal perforation caused by the ingestion of strong magnet have been reported ${ }^{2,3}$. We analyzed the clinical 
features of pediatric patients with multiple magnets ingestion in a single pediatric center,aim to emphasize the hazard of multiple rare-earth magnets ingestion and provide a reference for clinical practice.

\section{Methods}

We retrospectively reviewed the case records of all the patients less than 18 years old with multiple rareearth magnet ingestion in a university-affiliated pediatric medical center in China, from January 2016 to December 2019. Our hospital is a central children's hospital in east part of China. The service scope covers the whole province and several cities near the province. It has all pediatric subspecialties, including Emergency, Gastroenterology and General Surgery. The diagnoses of these patients were based on the history and the X-ray results. Those cases with single magnet ingestions were excluded. We collected all clinical data of these cases, including patient demographics, chief complaints, symptoms, physical signs, imaging data, endoscopy findings, surgical procedures, outcomes, and the followed-up information.

Descriptive counting data are represented by means (median) and the frequencies are reported as percentages. The independent sample T-test was used to compare the differences between the two groups. All reported $p$ values are two-tailed, and statistical significance was set at $p<0.05$. Statistical analysis was performed using IBM SPSS Statistics 20 (IBM Corp., Armonk, NY).

\section{Results}

\section{General data}

A total of 51 cases were included in this study. The mean age of these cases was 5.25 years, with a median age of 5.33 years, ranged from four months to ten years and 11 months. The proportion of male patients is higher than female patients as 70.6\% (36/51). From 2015 to 2019, the number of cases increased (4,8,6,14,19 respectively; Fig. 1$)$.

\section{Clinical manifestations}

The numbers of magnets ingested ranged from two to 24. Ingestion of two magnets accounted for the most as $41.2 \%$ (21/51) of the cases (Fig. 2). Among the 51 cases, the specific time of ingestion of six children is unknown. The average visiting time of the other 45 children was 46.75 hours after their ingestions, ranged from two hours to 14 days. Only 19 cases (37.3\%) were symptomatic, including 15 cases of abdominal pain, 12 cases of vomiting, two cases of fever and one case of chest pain. Nine patients had positive signs of abdominal tenderness, and four of them had peritoneal irritation signs (Table 1). 
Table 1

Clinical features and the outcomes

\begin{tabular}{|c|c|c|}
\hline \multirow[t]{6}{*}{ Symptoms, No. (\%) } & No & $32(62.7 \%)$ \\
\hline & Yes & 19(37.3\%) \\
\hline & Abdominal pain & $15(29.4 \%)$ \\
\hline & Nausea and vomiting & $12(23.5 \%)$ \\
\hline & Fever & $2(3.9 \%)$ \\
\hline & Chest pain & $1(2.0 \%)$ \\
\hline \multirow[t]{4}{*}{ Signs, No. (\%) } & No & $42(82.4 \%)$ \\
\hline & Yes & $9(17.6 \%)$ \\
\hline & Abdominal tenderness only & $9(17.6 \%)$ \\
\hline & Peritoneal irritation signs & $4(7.8 \%)$ \\
\hline \multirow[t]{7}{*}{ Radiograph tests, No. (\%) } & $\mathrm{X}$-rays & $51(100 \%)$ \\
\hline & Foreign bodies only & $49(96.1 \%)$ \\
\hline & Bowel obstruction & $2(3.9 \%)$ \\
\hline & CT scans & $6(11.8 \%)$ \\
\hline & Foreign bodies only & $2(3.9 \%)$ \\
\hline & Bowel obstruction & $3(5.9 \%)$ \\
\hline & Perforation & $1(2.0 \%)$ \\
\hline \multirow[t]{4}{*}{ Treatment, No. (\%) } & No intervention & $18(35.3 \%)$ \\
\hline & Endoscopy & $10(19.6 \%)$ \\
\hline & Surgery & $16(31.4 \%)$ \\
\hline & Endoscopy + surgery & $7(13.7 \%)$ \\
\hline \multirow[t]{6}{*}{ Outcomes, No. (\%) } & No adverse effects & $26(51.0 \%)$ \\
\hline & Mucosal injury & $2(3.9 \%)$ \\
\hline & Ulcer & $1(2.0 \%)$ \\
\hline & Magnets lodged in gastrointestinal tract & $2(3.9 \%)$ \\
\hline & Fistula & $1(2.0 \%)$ \\
\hline & Perforation & 3 (5.9\%) \\
\hline
\end{tabular}




\begin{tabular}{|c|c|c|}
\hline \multirow[t]{6}{*}{ Symptoms, No. (\%) } & No & $32(62.7 \%)$ \\
\hline & Yes & $19(37.3 \%)$ \\
\hline & Abdominal pain & $15(29.4 \%)$ \\
\hline & Nausea and vomiting & $12(23.5 \%)$ \\
\hline & Fever & $2(3.9 \%)$ \\
\hline & Chest pain & $1(2.0 \%)$ \\
\hline & Multiple perforations, adhesions and necrosis & $16(31.4 \%)$ \\
\hline
\end{tabular}

\section{Clinical Management}

All the patients were treated according to the process we developed and shown in the diagram (Fig. 3). All the 51 children had positive foreign body shadow on abdominal plain radiographs, of which two patients showed intestinal obstruction. Six cases also had CT examinations, which showed that three cases of intestinal obstruction, one case of intestinal perforation, and two cases of gastrointestinal foreign bodies only.

According to the radiograph, 17 cases' magnets may still be located in the upper digestive tract, so gastroduodenoscopies were performed. By gastroduodenoscopy, the magnets of five cases were removed, of which two cases had no complications, one case had slight mucosal injury and two cases had perforation. In one of these two cases, the location of perforation was duodenum and then the patient was transferred to surgery. The perforation of the other case was in the lower esophagus. After ten days of local drainage and enteral nutrition through Nasojejunal tube, the perforation healed. In six cases, the magnets had passed through the pylorus and entered the lower digestive tract, and the gastric mucosa had mild injury in one of these six cases. In the other six cases, the magnets were still in the upper digestive tract, but they were embedded in the mucosa and could not be removed by gastroduodenoscopy. So, these six cases were transferred to surgery.

In this study, a total of 23 children underwent surgery, including 21 cases of laparotomy and two cases of laparoscopy combined laparotomy. After the operation, four patients stayed in ICU for monitoring for two or three days. 24 patients fasted for an average of 7.5 days ranged from two to ten days. 22 patients had gastrointestinal decompression for an average of 6.8 days ranged from two to nine days. 16 patients had abdominal drainage for an average of 7.8 days ranged from five to nine days. 11 patients had fever after operation for an average of 2.7 days ranged from one to six days. 22 patients used antibiotics for average of 11.8 days ranged eight to 19 days.

The patients were divided into two groups according to whether they were operated or not. Compared with the non-surgical group, the surgical group had more male cases $(21 / 23 \mathrm{vs} 15 / 28, p=0.004)$, and the 
time of visiting was longer (80(72) vs $26(5)$, hours, $p=0.008)$. While, there was no significant difference in the mean age and the number of swallowing magnets (Table 2). This suggests that patients should see a doctor as soon as possible after multiple rare-earth digestion. The longer the time is, the more likely patients have to suffer from surgical operation.

Table 2

Difference between surgical and non-surgical group

\begin{tabular}{|llll|}
\hline & Surgery$(\mathbf{n}=23)$ & No surgery $(\mathbf{n = 2 8 )}$ & P value \\
\hline Age, years & $4.6(3.8)$ & $5.9(6.5)$ & 0.155 \\
\hline Gender, No (\%) & & & 0.004 \\
\hline Male & $21(91)$ & $15(54)$ & \\
\hline Female & $2(9)$ & $13(46)$ & 0.184 \\
\hline The number of magnets & $6(4)$ & $4(3)$ & 0.008 \\
\hline Time after swallow, hours & $80(72)$ & $26(5)$ & \\
\hline
\end{tabular}

\section{Outcome}

Among the 51 cases, the magnets passed naturally for $47.1 \%$ (24/51); were removed by endoscopies for $9.8 \%(5 / 51)$ and by surgeries for $43.1 \%(22 / 51)$. The complications include mucosal injury for two cases, ulcer for one case, magnets lodged in the gastrointestinal tract for two cases, fistula for one case, perforation for three cases and multiple gastrointestinal injuries for 13 cases. The multiple gastrointestinal injuries included perforations, adhesions, and necrosis. In the most serious case, there were 11 intestinal perforations, three intestinal necrosis, and extensive intestinal adhesion. In this study, 39 patients were hospitalized, the average length of stay was 8.8(one-nine) days. No death happened in these cases. We followed up these patients for at least two months. There were no long-term complications such as obstruction or infection.

\section{Discussion}

Rare-earth magnets are not the most common foreign body that children swallow compared to others,but they require special attention because of the hazard. In the past ten years, we have seen several reports of serious complications caused by multiple magnet ingestion from many countries including $\mathrm{China}^{3-5}$. So, the USA government forced toy companies to recall certain magnetic toys. Then, in some areas of USA, the incidence of multiple magnet ingestion decreased ${ }^{6}$. In China, although there are warning labels on the toy packages, the incidence of multiple magnets ingestions is increasing. Just as our data shows, the number of patients in 2019 is about four times up compared to 2015. 
Previous studies show that $80-90 \%$ of the foreign bodies pass spontaneously, only $1-5 \%$ of the cases require surgical intervention ${ }^{1,7}$. However, in our study, the surgical intervention rate was as high as $45.1 \%$ and similar to other studies ${ }^{3}$.

The magnetic force of the rare-earth magnet is 30-50 times stronger than that of the ordinary magnet and each rare-earth magnet can attract 640 times the weight of its own. After multiple rare-earth magnets were swallowed, they attracted each other tightly, resulting in local compression of the intestinal wall, ischemia, necrosis, perforation, internal fistula, peritonitis, intestinal obstruction and even death ${ }^{8}$. Rareearth magnets in toys that children swallowed are generally small, and the perforation caused by them is also small. In some cases, because of the wrapping of omentum after perforation or the formation of internal fistula directly, the clinical symptoms are mild and the imaging performances are not typical. In this study, 20 cases had perforation, fistula, and obstruction, but five of them had mild or no symptoms and only four cases had the typical changes in the radiographs, which similar to several other reports ${ }^{4,9-11}$. Some children cannot provide the exact time of swallowing the magnets, which may delay the diagnosis and the treatment. It is one of the causes of serious complications. In this study, a 3-yearold boy had no symptom and was diagnosed 14 days after he swallowed the magnets when the small intestine perforation had already formed. Another reason is that in some cases the number of magnets swallowed is also not accurate. It may lead to the situation that multiple magnets are attracted tightly and mistaken for a single one. Another 5-year-old patient in this study swallowed the magnets for an unknown time. The initial diagnosis in the local hospital was one magnet swallowed. But during the observation process, the child developed abdominal pain, and then he was transferred to our hospital for surgery and found that there were multiple magnets. Therefore, for the cases with an inaccurate number of magnets swallowed, it is necessary to treat them as multiple magnets swallowed and try multi-position photography to figure out the number of magnets. For patients considering a single magnet swallowed, follow-up observation is also necessary. If the magnet position is fixed, the necessary intervention should be done ${ }^{8}$.

For the treatment of magnetic foreign bodies in children digestive tract, different guidelines have different opinions. The ESGE/ESPGHAN guideline 2017 recommends urgent ( $<24$ hours) removal of all magnets within endoscopic reach. For those beyond endoscopic reach, the guideline advises that close observation and surgical consultation ${ }^{12}$. The NASPGHAN guideline 2015 recommends different managements based on the single magnet ingestion or multiple magnet ingestion. For single magnet, this guideline recommends removal if possible or confirm passage with serial x-rays. For all multiple magnets within the stomach or esophagus, this guideline recommends removal by endoscopy if the time $<12$ hours. While $>12$ hours until the time of the procedure, this guideline recommends consulting pediatric surgery prior to endoscopic removal. For those multiple magnets beyond the stomach, the patient could be treated by enteroscopy or colonoscopy for removal if asymptomatic or follow with serial $x$-ray to check for progression ${ }^{1}$. But if symptomatic, the patient should be referred to pediatric surgery ${ }^{1}$. In this study, patients were managed as the following algorithm (Fig. 3) which was based on the guideline and the actual situation of our center. For the patients with perforation and fistula found after endoscopic 
removal, the general treatment is to switch to surgery ${ }^{13}$. However, one patient in this study had a fistula from the lower esophagus to the cardia. After the removal, the fistula contracted and the wound was small. So, we did not do surgery operation but gave gastric tube decompression and stopped his oral diet. No symptoms such as pneumoperitoneum and abdominal pain occurred. After 10 days, gastroscope was reexamined and the wound healed well. Then the patient restored oral diet and was discharged smoothly. There is also another case report shows that the patient with mild symptoms of fistula did not undergo surgery and recovered smoothly after removal of the magnets by endoscopy ${ }^{14}$.

Our study has several limitations. It is a retrospective chart review from a single hospital, which is limited by the quality of documentation and the number of cases. Moreover, some of the patients just follow-up for two months. It may be possible that some of the results cannot be sustained over a longer period time.

\section{Conclusions}

As multiple rare-earth magnets can cause serious gastrointestinal injury and have a high risk of requiring intervention for removal, primary prevention is very important. Maybe the government of China could do some efforts to restrict the sale of high-powered magnetic sets containing small magnets and so to reduce children's access to these hazardous consumer products. And for parents and physicians, it is necessary to be aware of the dangers associated with the ingestion of multiple rare-earth magnets. If such ingestions are suspected, medical attention should be prompted.

\section{Abbreviations}

NdFeB: Neodymium iron boron

ICU: Intensive care unit

\section{Declarations}

\section{Ethical approval and consent to participate}

The study protocol was approved by the Research Ethics Committee of Children's Hospital of Nanjing Medical University (NO. 202004035-1).

\section{Consent for publication}

Not applicable.

\section{Availability of data and materials}




\section{Competing interest}

All authors report no conflicts of interests.

\section{Funding}

This study was not funded by any grants.

\section{Authors' contributions}

Yucan Zheng contributed to the study design, data collection, data analysis and manuscript preparation. Zhihua Zhang and Kunlong Yan contributed to the data collection. Hongmei Guo and Mei Li assisted study design, interpreted the data, and revised the manuscript. Min Lian and Zhifeng contributed to the study design and critically revised the manuscript.

\section{Acknowledgements}

We would like to thank all the staff involved in these cases of our hospital for their help in collection of the patients' clinical data.

\section{References}

1. Kramer RE, Lerner DG, Lin T et al. Management of ingested foreign bodies in children: a clinical report of the NASPGHAN Endoscopy Committee. J Pediatr Gastroenterol Nutr. 2015; 60: 562-74.

2. Agbo C, Lee L, Chiang V et al. Magnet-related injury rates in children: a single hospital experience. J Pediatr Gastroenterol Nutr. 2013; 57: 14-7.

3. Sola R Jr, Rosenfeld EH, Yu YR, St Peter SD, Shah SR. Magnet foreign body ingestion: rare occurrence but big consequences. J Pediatr Surg. 2018; 53: 1815-9.

4. Miyamoto R, Okuda M, Kaneko K, Numoto S, Okumura A. Multiple magnets ingestion followed by intestinal fistula with mild symptoms. Glob Pediatr Health. 2019; 6: 2333794X19855805.

5. Si X, Du B, Huang L. Multiple Magnetic Foreign Bodies Causing Severe Digestive Tract Injuries in a Child. Case Rep Gastroenterol. 2016; 10: 720-7.

6. Rosenfield D, Strickland M, Hepburn CM. After the Recall: Reexamining Multiple Magnet Ingestion at a Large Pediatric Hospital. J Pediatr. 2017; 186: 78-81.

7. Hariga I, Khamassi K, Zribi S et al. Management of foreign bodies in the aerodigestive tract. Indian $\mathrm{J}$ Otolaryngol Head Neck Surg. 2014; 66: 220-4. 
8. Hodges NL, Denny SA, Smith GA. Rare-Earth Magnet Ingestion-Related Injuries in the Pediatric Population: A Review. Am J Lifestyle Med. 2015; 11: 259-63.

9. Taher H, Azzam A, Khowailed O, Elseoudi M, Shaban M, Eltagy G. A case report of an asymptomatic male child with multiple entero-enteric fistulae post multiple magnet ingestion. Int J Surg Case Rep. 2019; 58: 50-3.

10. Zachos K, Panagidis A, Georgiou G, Alexopoulos V, Sinopidis X. Double Jejunoileal Fistula after Ingestion of Magnets. J Indian Assoc Pediatr Surg. 2019; 24 :63-4.

11. Tacher H, Azzam A, Khowailed O, Elseoudi M, Shaban M, Eltagy G. A case report of an asymptomatic male child with multiple entero-enteric fistulae post multiple magnet ingestion. Int J Surg Case Rep. 2019; 58: 50-3.

12. Tringali A, Thomson M, Dumonceau JM et al. Pediatric gastrointestinal endoscopy: European Society of Gastrointestinal Endoscopy (ESGE) and European Society for Pediatric Gastroenterology Hepatology and Nutrition (ESPGHAN) Guideline Executive summary. Endoscopy. 2017; 49: 83-91.

13. Cho J, Sung K, Lee D. Magnetic foreign body ingestion in pediatric patients: report of three cases. BMC Surg. 2017; 17: 73.

14. Phen C, Wilsey A, Swan E, Falconer V, Summers L, Wilsey M. Non-Surgical Management of Gastroduodenal Fistula Caused by Ingested Neodymium Magnets. Pediatr Gastroenterol Hepatol Nutr. 2018; 21: 336-40.

\section{Figures}

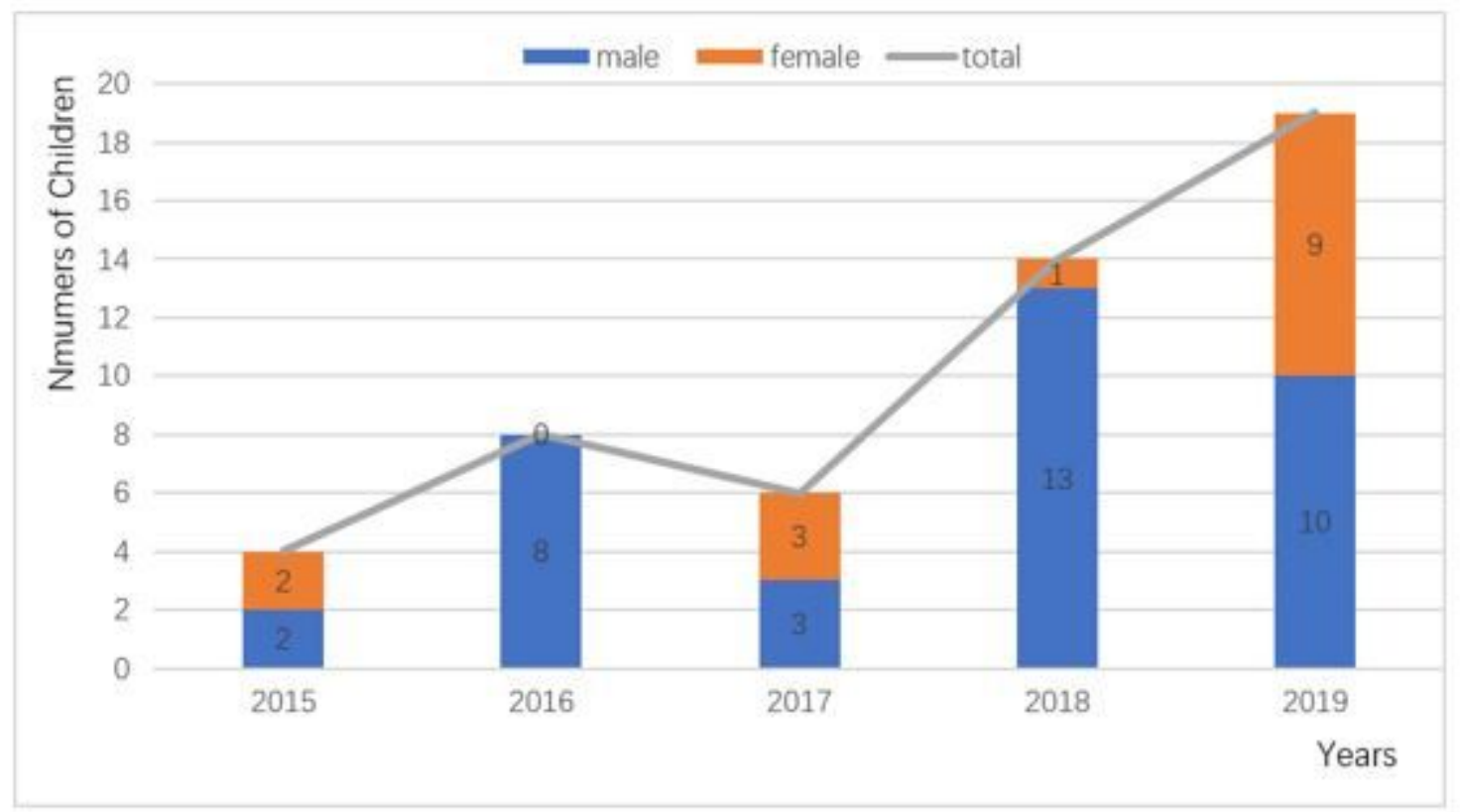

\section{Figure 1}

Numbers of children swallowed multiple magnets each year from 2015 to 2019 


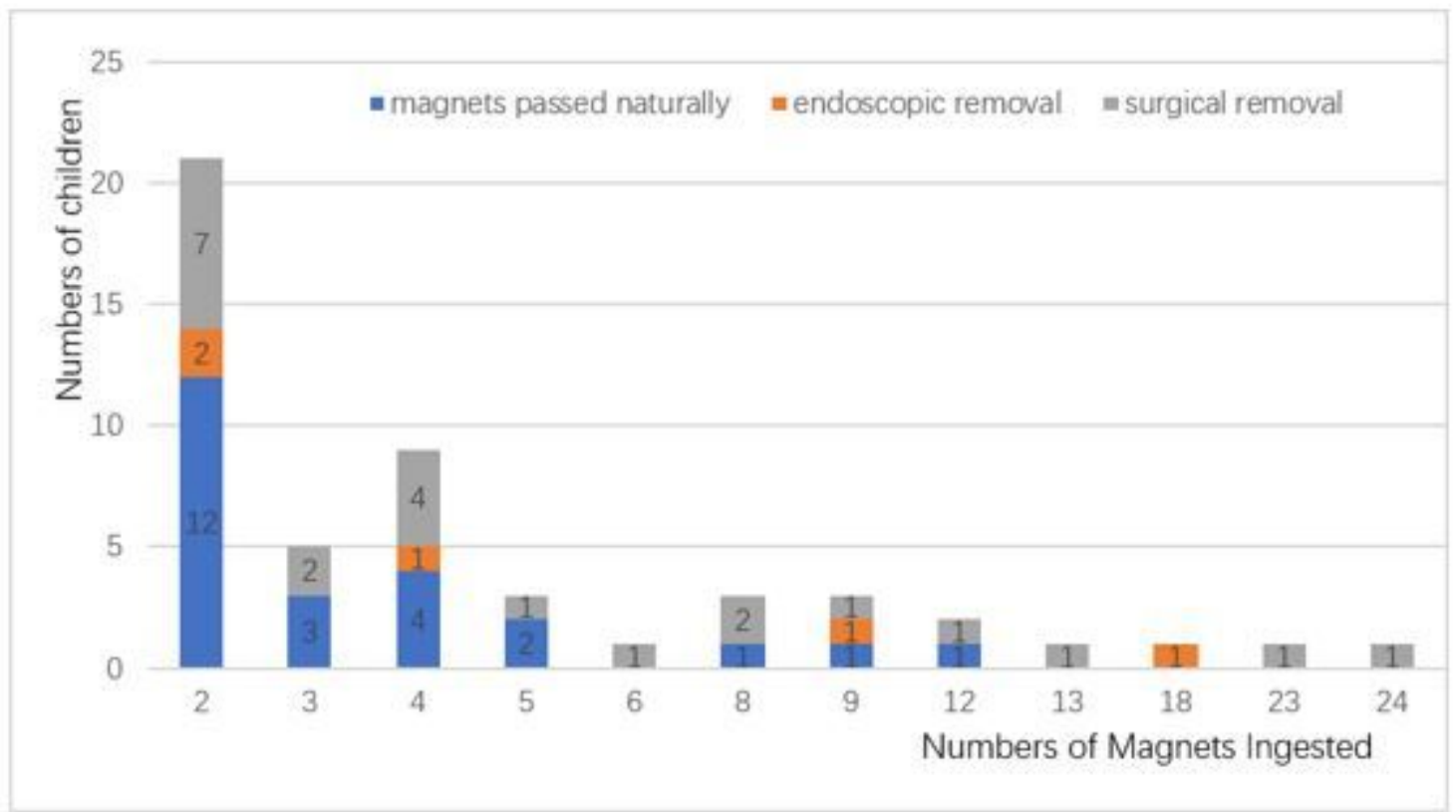

Figure 2

Numbers of magnets children swallowed

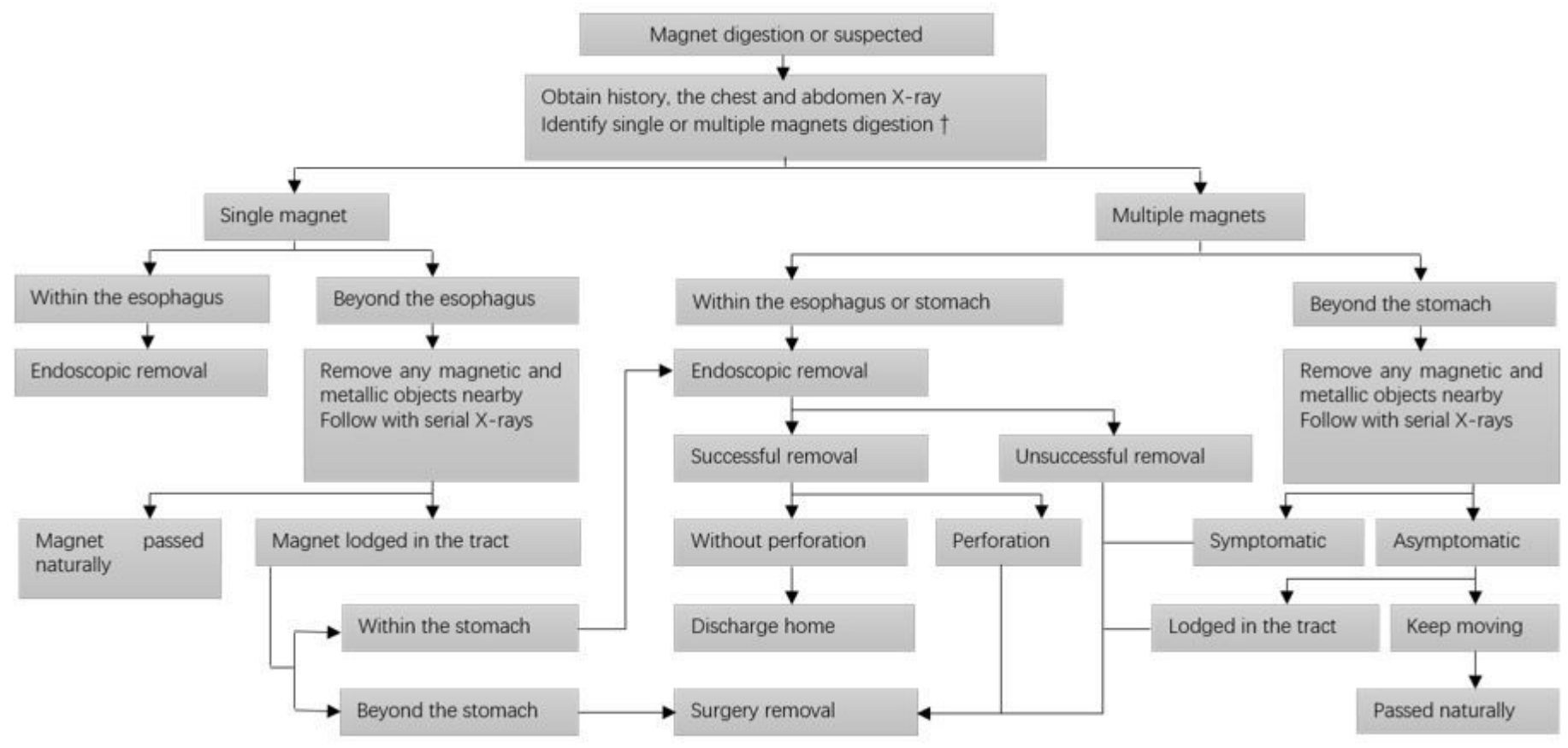

Figure 3

Algorithm of rare-earth magnet ingestion management in children tIf a single magnet or multiple magnet ingestion cannot be defined then consider as multiple magnets. †Single magnet and metallic object consider as multiple magnets. 